\title{
Berbamine Exerts Anti-Inflammatory Effects via Inhibition of NF-KB and MAPK Signaling Pathways
}

\author{
Xiao-Jian Jia ${ }^{a, b} \quad$ Xi Lib ${ }^{b}$ Feng Wang ${ }^{a, b}$ Han-Qing Liu ${ }^{b}$ Da-Jun Zhang ${ }^{c}$ Yun Chen \\ aShenzhen Kangning Hospital \& Shenzhen Mental Health Center, bShenzhen Key Laboratory for Drug \\ Addiction and Medication Safety, Peking University Shenzhen Hospital, Shenzhen Peking University \\ - The Hong Kong University of Science and Technology Medical Center, Shenzhen, 'Department of \\ Chemistry, Shenyang Medical College, Shenyang, PR China
}

\section{Key Words}

Berbamine $\cdot$ Macrophages $•$ Neutrophils $•$ Peritonitis $・ N F-\kappa B \cdot M A P K$

\begin{abstract}
Background/Aims: This study aimed to investigate the anti-inflammatory activity of Berbamine (BER), a bisbenzylisoquinoline alkaloid extracted from Berberis amurensis (Xiao Bo $A n)$, and the underlying mechanisms. Methods: Macrophages and neutrophils were treated with BER in vitro and stimulated with LPS and fMLP. The effects of BER on the expression of proinflammatory mediators in macrophages were evaluated with quantitative RT-PCR and ELISA. The effects of BER on the activation and superoxide release of neutrophils were determined with flow cytometry and WST-1 reduction test. The inhibitory effects of BER on the activation of signaling pathways related to inflammatory response in macrophages were evaluated by western blot analysis. In addition, a mouse peritonitis model was made by peritoneal injection of thioglycollate medium and anti-inflammatory effects of BER were investigated in vivo by quantitative analysis of pro-inflammatory factor production and leukocyte exudation. Results: BER significantly inhibited inflammatory factor expression by LPS-stimulated macrophages and suppressed activation and superoxide release of fMLP-stimulated neutrophils. In the mouse peritonitis model, BER significantly inhibited the activation of macrophages and exudation of neutrophils. According to analysis, BER significantly suppressed phosphorylation of NF-KB and MAPK (JNK and ERK1/2) signaling pathways in LPS-stimulated macrophages. Conclusions: Collectively, data from this study suggest that BER has anti-inflammatory potential, which is effected via inhibition of NF-KB and MAPK signaling pathways, and thus holds promise for treatment of inflammatory disease.
\end{abstract}

\section{Introduction}

A properly-regulated inflammatory response protects the host from infection and aids in restoring structure and function of damaged tissues after injury. However, severe or persistent inflammation may lead to a variety of serious acute and chronic diseases, such 
as systemic inflammatory response syndrome, acute lung injury and inflammatory bowel disease [1-6].

During inflammation, macrophages are first activated by inflamed tissues, whereupon macrophages secrete pro-inflammatory mediators, including tumor necrosis alpha (TNF- $\alpha$ ), interleukin-6 (IL-6), interleukin-1 $\beta$ (IL-1 $\beta$ ), prostaglandin E2 (PGE2), Matrix metalloproteinase (MMP)-2 and MMP-9 [1-3, 7-9]. As a result, neutrophils are rapidly recruited from the bloodstream to inflamed tissues where they release reactive oxygen species (ROS) and pro-inflammatory factors [4-6, 9]. Over-activation of macrophages and neutrophils has been reported to exacerbate acute and chronic inflammatory disorders. Many studies reveal that the ability to inhibit production of pro-inflammatory factors by macrophages and neutrophils shows promise for treatment inflammatory diseases [16]. Therefore, the identification of inhibitory agents is a practical pathway for treatment inflammatory diseases.

Berbamine is a structurally-unique bisbenzylisoquinoline alkaloid, identified from the Traditional Chinese Medicine plant, Berberis amurensis (Xiao Bo An). Two decades ago, some studies reported that BER and its derivatives exhibited anti-inflammatory activity by inhibiting the expression and secretion of inflammatory mediators through macrophages or neutrophils in vitro. It was also reported that BER exerted inhibitory effects on subcutaneous air pouch inflammation in vivo. However, the pharmacological mechanisms underlying antiinflammatory activity were not comprehensively revealed at that time, hindering appropriate BER therapy applications [10-12]. In recent years, anti-tumor activities have been reported for BER and its derivatives on various types of cancers, including lymphoma, myeloma, lung and breast cancers. Furthermore, anti-tumor studies report that BER significantly inhibits the NF- $\kappa B$ signaling pathway, a key signaling pathway for inflammation response [13-16]. Hence, BER and its derivatives may exert anti-inflammatory effects via inhibition of the NF$\kappa \mathrm{B}$ signaling pathway for macrophages and neutrophils, yielding an agent with promise for treatment of inflammatory diseases. To comprehensively reveal anti-inflammatory activity by BER, both in vitro and in vivo experiments were performed.

\section{Materials and Methods}

\section{Reagents}

Berbamine hydrochloride (BER), lipopolysaccharide (LPS) from Escherichia coli 055: B5, N-FormylMet-Leu-Phe (fMLP), and a cell apoptosis assay kit was purchased from Sigma Chemicals Co. (St. Louis, MO, USA). TransScript First-Strand cDNA Synthesis Kit and TransStart Top Green qPCR Kit were purchased from Transgen Biotech Co. (Beijing, China). ELISA kits for determining TNF- $\alpha$, IL-6, IL-1 $\beta$ and PGE2 were purchased from R\&D Systems (Minneapolis, MN, USA). A superoxide assay kit (S0060) was purchased from Beyotime Co. (Jiangsu, China). Monoclonal antibodies for flow cytometry, APC-conjugated (allophycocyanin) antiGr-1, FITC (fluorescein isothiocyanate)-conjugated (fluorescein isothiocyanate) anti-CD11b, PE-conjugated (phycoerythrin) anti-F4/80 and PE-conjugated anti-CD62L were obtained from BD Pharmingen (Franklin

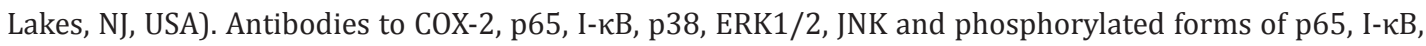
p38, ERK1/2 and JNK were purchased from Cell Signaling Technology (Beverly, MA, USA).

\section{Cell culture}

The murine macrophage cell line, RAW264.7, was obtained from Peking Union Medical College and maintained in high glucose DMEM medium, supplemented with $10 \%$ heat-inactivated FBS, 100U/ml penicillin and $100 \mu \mathrm{g} / \mathrm{ml}$ streptomycin at $37^{\circ} \mathrm{C}$ under $5 \% \mathrm{CO}_{2}$.

Mouse neutrophils were isolated from the bone marrow of femurs and tibias by hypotonic lysis, followed by Percoll (GE Healthcare, Piscataway, NJ USA) gradient centrifugation as described. Before activation, cells were kept in IMDM medium, both with and without supplementation by $2 \%$ heat-inactivated FBS at $37^{\circ} \mathrm{C}$ under $5 \% \mathrm{CO}_{2}$. 


\section{Cellular Physiology Cell Physiol Biochem 2017;41:2307-2318 \\ \begin{tabular}{l|l} 
and Biochemistry Published onlıne: April 26, 2017 & $\begin{array}{l}\text { (c) } 2017 \text { The Author(s). Published by S. Karger AG, Basel } \\
\text { www.karger.com/cpb }\end{array}$
\end{tabular}}

Jia et al.: Berbamine Exerts Anti-Inflammatory via Inhibition of NF-KB and MAPK Pathways

\section{Peritonitis}

Male BALB/c mice (6-8 weeks old) were purchased from Charles River Laboratory, China (Beijing), and maintained under specific pathogen-free conditions at $22 \pm 2{ }^{\circ} \mathrm{C}$ and $55 \pm 10 \%$ humidity, on a $12 \mathrm{~h} / 12$ $\mathrm{h}$ light/dark cycle. All protocols conform to National Institutes of Health (NIH) guidelines, and animal care was performed in compliance with the Principles of Laboratory Animal Care. The study was approved by the Ethical Committee on Animal Research in Beijing University of Traditional Chinese Medicine (Beijing, China).

Mice were randomly assigned to the following five groups, (each group, $n=6$ ), named: Vehicle, Thioglycollate medium (TM), TM + Dexamethasone (DEX, $5 \mathrm{mg} / \mathrm{kg}$ ), TM + BER (5 mg/kg), TM + BER (25 mg/kg). TM + BER groups received an intragastric bolus of BER (5 or $25 \mathrm{mg} / \mathrm{kg}$, dissolved in 0.5 $\%$ carboxymethylcellulose sodium). Vehicle group, TM group and TM + DEX groups received $0.5 \%$ carboxymethylcellulose sodium (CMC-Na (10 ml/kg). One hour after intragastric administration of BER, 3 $\%$ TM was given to all TM groups by intraperitoneal injection ( $2 \mathrm{ml} / \mathrm{mouse}$ ), and an equal volume of $0.9 \%$ $\mathrm{NaCl}$ solution was given to the Vehicle group. At $4 \mathrm{~h}$ post-TM administration, subject peritonea were lavaged with $5 \mathrm{ml}$ of PBS, which lavage fluids were then collected.

\section{Cell viability}

The RAW264.7 cells were inoculated to 96-well plates, where they incubated for $24 \mathrm{~h}$ before the cells were incubated again, with or without BER, for another $24 \mathrm{~h}$. Next, the cell medium was discarded and 100 $\mu \mathrm{l}$ of $0.5 \mathrm{mg} / \mathrm{ml}$ MTT was added, then incubated for $4 \mathrm{~h}$, after which the MTT solution was discarded and 150 $\mu \mathrm{l}$ of dimethyl sulfoxide was added to each well to dissolve the crystals. Once culture steps were complete, plates were detected at a wavelength of $570 \mathrm{~nm}$ on a microplate reader. Optical density (OD) values are used to indicate levels of cell viability.

\section{RNA extract and real-time PCR}

RAW264.7 cells were seeded in 6-well plates. After $24 \mathrm{~h}$ of incubation, the cells were pretreated with BER for $1 \mathrm{~h}$, then stimulated by LPS $(0.1 \mu \mathrm{g} / \mathrm{ml})$ for $6 \mathrm{~h}$. Using an Reverse Transcription kit (Promega, Madison, WI, USA), sample total RNA was subsequently extracted and reverse-transcribed to cDNA at $42{ }^{\circ} \mathrm{C}$ for $30 \mathrm{~min}$, which was in turn amplified using PCR Supermix kit. Sequences of the GAPDH, TNF- $\alpha$, IL-6, IL-1 $\beta$, COX2, MMP-2 and MMP-9 primers appear in Table 1. Amplification reactions were performed for one cycle at $95{ }^{\circ} \mathrm{C}$ for $1 \mathrm{~min}$, then 40 cycles at $95^{\circ} \mathrm{C}$ for $5 \mathrm{~s}$ and $60{ }^{\circ} \mathrm{C}$ for $40 \mathrm{~s}$, followed by one cycle of melting curve determination. The amount of mRNA in each sample was calculated and normalized to the levels of GAPDH mRNA.[17-19]

\section{Measurement of cytokines by ELISA}

RAW264.7 cells were seeded in 96-well plate and incubated for $24 \mathrm{~h}$, after which the cells were pretreated with BER for $1 \mathrm{~h}$, then stimulated with LPS for $6 \mathrm{~h}$. Applying ELISA, cell medium levels of TNF- $\alpha$, IL-6, IL-1 $\beta$, PGE2 MMP-2 and MMP-9 were then measured.

From inoculated and lavaged mouse peritonea, the lavage fluids were concentrated and resulting supernatants collected, from which levels of TNF- $\alpha$ and IL- 6 were quantified by ELISA.

\section{Flow cytometry}

To measure the cytotoxicity of BER on neutrophils, isolated neutrophils were seeded in 24-well plates, which cells were pretreated with BER for $1 \mathrm{~h}$, then cultured with or without fMLP $(1 \mu \mathrm{M})$ stimulation for $12 \mathrm{~h}$.
Table. 1. Primer sequences used for RT-PCR

\begin{tabular}{|c|c|}
\hline Genes & Primer sequence \\
\hline \multirow[t]{2}{*}{$\mathrm{TNF} \alpha$} & forward 5'-CCССТTTATTGTCTACTCСТ-3' \\
\hline & reverse 5'-AAAGCCCATTTGAGTCCTTG-3' \\
\hline \multirow[t]{2}{*}{ IL-6 } & forward 5'-AAATAGTCCTTCCTACCCCAA-3' \\
\hline & reverse 5'-CCGAGTAGATCTCAAAGTGAC-3' \\
\hline \multirow[t]{2}{*}{ IL-1 $\beta$} & forward 5'-GAGCCCATCCTCTGTGACTC-3' \\
\hline & reverse 5'-TCAGCTCATATGGGTCCGACA-3' \\
\hline \multirow[t]{2}{*}{$\operatorname{cox} 2$} & forward 5'-TCAATACTGGAAGCCGAGCA-3' \\
\hline & reverse 5'-CACCCCTTCACATTATTGCAGA-3' \\
\hline \multirow[t]{2}{*}{ MMP-2 } & forward 5'-GACTCCTGGAATGCCATCCCT-3' \\
\hline & reverse 5'-TGCTTCCAAACTTCACGCTCT-3' \\
\hline \multirow[t]{2}{*}{ MMP-9 } & forward 5'-TGCCCTGGAACTCACACGA-3' \\
\hline & reverse 5'-TTTGGAAACTCACACGCCAGA-3' \\
\hline \multirow[t]{2}{*}{ GAPDH } & forward 5'-GCGACTTCAACAGCAACTCC-3' \\
\hline & reverse 5'-CACCCTGTTGCTGTAGCCGT-3' \\
\hline
\end{tabular}




\section{Cellular Physiology Cell Physiol Biochem 2017;41:2307-2318 \\ \begin{tabular}{ll|l} 
and Biochemistry Published onlıne: April 26, 2017 & $\begin{array}{l}\text { C } 2017 \text { The Author(s). Published by S. Karger AG, Basel } \\
\text { www.karger.com/cpb }\end{array}$ \\
\hline
\end{tabular}

Stimulated cells were next collected, stained with FITC-conjugated (fluorescein isothiocyanate) Annexin $\mathrm{V}$ and propidium iodide following the manufacturer's instruction, then analyzed on a FACS-Canto II(BD Biosciences). Apoptotic neutrophils are here defined as Annexin V-positive but propidium iodide-negative cells.

To determine the effects of BER on activation of neutrophils, isolated neutrophils were seeded in 24 well-plates, then pretreated with BER for $1 \mathrm{~h}$ before stimulation with fMLP $(1 \mu \mathrm{M})$ for $2 \mathrm{~h}$. Thus-prepared cells were collected, suspended in staining buffer (1\% BSA in PBS), then stained with FITC-conjugated anti$\mathrm{CD} 11 \mathrm{~b}$ and PE-conjugated anti-CD62L at $4{ }^{\circ} \mathrm{C}$ for $30 \mathrm{~min}$. Finally, the conjugated samples were washed with staining buffer and analyzed by flow cytometry.

From inoculated mice, peritoneal lavage fluids were concentrated, suspended in staining buffer and stained with APC-conjugated anti-Gr-1, FITC-conjugated anti-CD11b and PE-conjugated anti-F4/80 at $4{ }^{\circ} \mathrm{C}$ for $30 \mathrm{~min}$. Then, the samples were washed and analyzed by flow cytometry. Identification of macrophages was based on positive labeling for F4/80 and CD11b, while neutrophils were identified by positive labeling for Gr-1 and CD11b.

Superoxide release determination

Isolated neutrophils were suspended in superoxide assay buffer, then incubated with BER $37^{\circ} \mathrm{C}$ for 30 min, after which respiratory burst was stimulated by fMLP $(1 \mu \mathrm{M})$ for $2 \mathrm{~h}$. Superoxide release was determined by WST-1 (water-soluble tetrazolium salts) reduction test according to the manufacture's protocol.

\section{Western blot analysis}

To prepare for blot analysis, RAW264.7 cells were seeded in 6-well plates and incubated for $24 \mathrm{~h}$, after which the cells were pretreated with BER for $1 \mathrm{~h}$, then stimulated by LPS for 30 min or $6 \mathrm{~h}$. Once stimulated, the cells were collected using a cell scraper and total cell proteins were extracted by RIPA lysis buffer.[20] Next, proteins were separated by $10 \%$ SDS-PAGE and transferred to polyvinylidenedifluoride membranes. The protein-bearing membranes were then blocked in $5 \%$ skim milk for $1 \mathrm{~h}$ and incubated overnight at $4{ }^{\circ} \mathrm{C}$ with antibodies against p65, I- $\mathrm{kB}, \mathrm{p} 38$, ERK1/2, JNK, phosphorylated p65, phosphorylated I- $\kappa$ B phosphorylated p38, phosphorylated ERK1/2, phosphorylated JNK and COX2. Incubated protein membranes were then rinsed and incubated once again with horseradish peroxide-conjugated secondary antibodies for $2 \mathrm{~h}$ at room temperature, and rinsed once more. The resulting bands were visualized using ECL (enhanced chemiluminescence) reagents and band density analysis was performed using Quantity One (Bio-Rad, California, USA).

\section{Statistical analysis}

All data are here expressed as mean \pm standard error (SEM) of values from at least three independent experiments. Statistical analyses were performed with GraphPad Prism 5.0. One-way ANOVA was used to evaluate the difference among multiple groups and Dunnett's test was followed to compared the difference between two groups. P values less than 0.05 were considered to be statistically significant.

\section{Results}

Effects of BER on cell viability of RAW264.7 cells and apoptosis of neutrophils

The potential cytotoxicity of BER on RAW264.7 cells was evaluated by MTT assay, from which results (Fig. $1 \mathrm{~A}$ ) show that BER at the concentration up to $50 \mu \mathrm{M}$, but not $100 \mu \mathrm{M}$, had no cellular toxicity on RAW264.7 cells.

The apoptosis analysis results (Fig. 1 B) also show that BER had no pro-apoptosis effects on neutrophils at concentrations up to $50 \mu \mathrm{M}$, while at the concentration of $100 \mu \mathrm{M}$ had significantly pro-apoptosis effects.

Effects of BER on LPS-induced cytokine expression and secretion by macrophages

Macrophages play a key role during inflammatory response initiation and exert proinflammatory effects by secreting cytokines, such as TNF- $\alpha$, IL- 6 and IL- $1 \beta$. Therefore, we investigated the effects of BER on LPS-induced TNF- $\alpha$, IL- 6 and IL-1 $\beta$ expression, as well as 


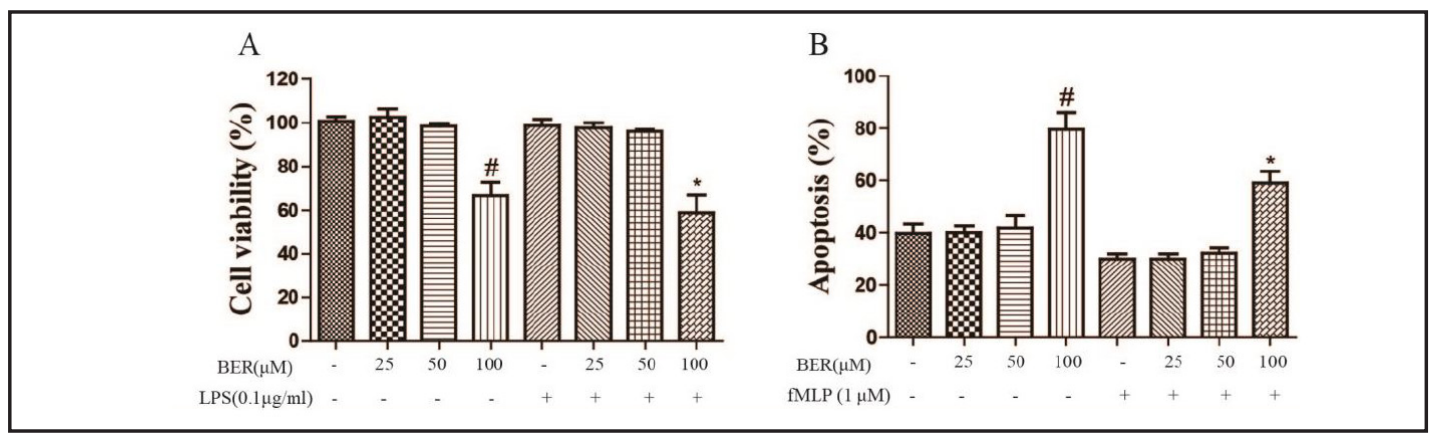

Fig. 1. Effects of BER on cell viability of RAW264.7 cells and apoptosis of neutrophils. RAW264.7 cells were pretreated with various concentrations of BER for $1 \mathrm{~h}$, then cultured either with LPS $(0.1 \mu \mathrm{g} / \mathrm{ml})$ stimulation, or without, for $24 \mathrm{~h}$. Cell viability was determined by MTT assay (A). Isolated neutrophils were pretreated with various concentrations of BER for $1 \mathrm{~h}$, then cultured with fMLP (10M) stimulation, or without, for $12 \mathrm{~h}$. Cells were stained with FITC-conjugated annexin $\mathrm{V}$ and propidium iodide, and the percentages of apoptotic cell were analyzed by flow cytometry (B). \# P<0.05 vs. Vehicle, ${ }^{*} \mathrm{P}<0.05$ vs. LPS or fMLP.

Fig. 2. Effects of BER on LPS-induced cytokine expression and secretion by macrophages. RAW264.7 cells were pretreated with various concentrations of BER for $1 \mathrm{~h}$ and then stimulated with LPS $(0.1 \mu \mathrm{g} / \mathrm{ml})$ for $6 \mathrm{~h}$. The expression and secretion of TNF- $\alpha$, IL- 6 and IL-1 $\beta$ was determined by RT-PCR (A, B, C) and ELISA (D, E, $F)$. Data were obtained from 3 independent experiments: \# $\mathrm{P}<0.05$ vs. Vehicle, ${ }^{*} \mathrm{P}<0.05$ vs. LPS alone.

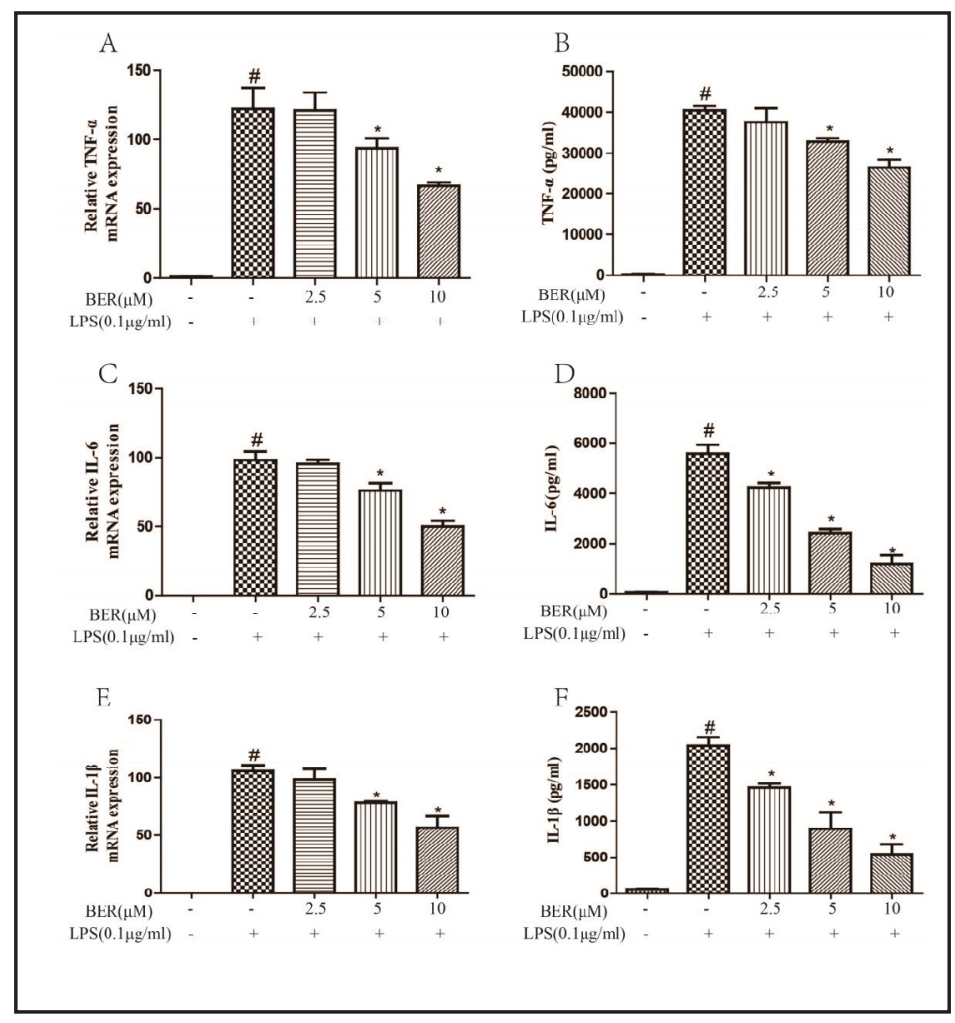

secretion by macrophages. The results (Fig. 2) indicate that BER significantly suppresses mRNA transcription and protein secretion of TNF- $\alpha$, IL- 6 and IL- $1 \beta$ by macrophages in a dose-dependent manner at 2.5-10 $\mu \mathrm{M}$.

\section{Effects of BER on the expression of COX2 and the production of PGE2 by macrophages}

COX2 plays an important role in inflammatory response by catalyzing synthesis of PGE2, producing inflammatory algesthesia. As well, test results of BER effects on COX2 expression and PGE2 production by macrophages (Fig. 3) demonstrate that BER significantly suppresses mRNA transcription and protein expression of COX2, as well as suppressing PGE2 production. Similarly, BER plays the roles in a dose-dependent manner at 2.5-10 $\mu \mathrm{M}$. 

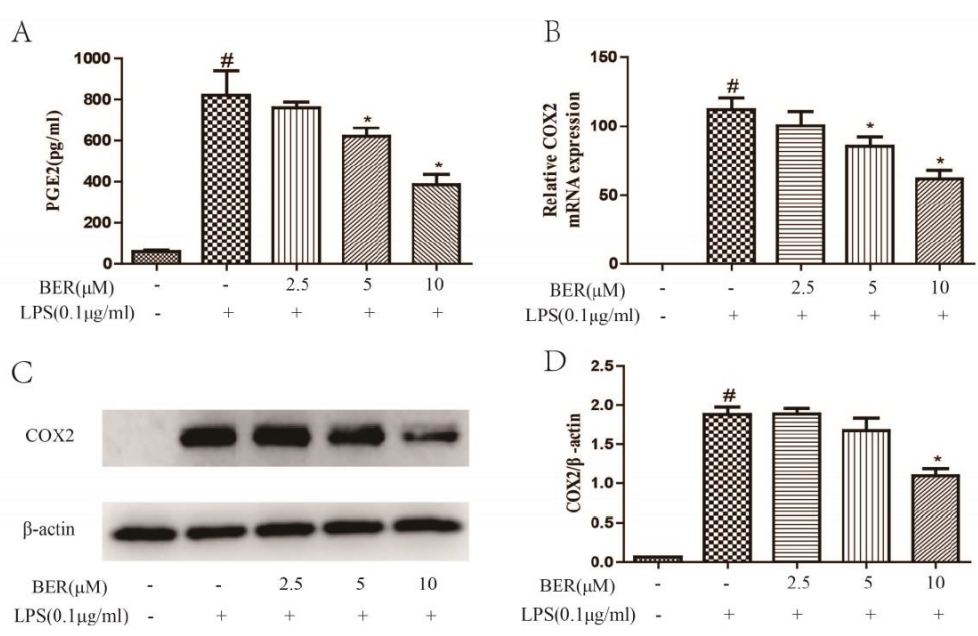

Fig. 3. Effects of BER on LPS-induced COX2 expression and PGE2 production. RAW264.7 cells were pretreated with various concentrations of BER for $1 \mathrm{~h}$ and then stimulated with LPS (0.1 $\mu \mathrm{g} / \mathrm{ml})$ for $6 \mathrm{~h}$. PGE2 production (A) was determined by ELISA and the expression of COX2 was determined by RT-PCR (B) and Western blot (C and D). Data was obtained from three independent experiments: \# $\mathrm{P}<0.05$ vs. Vehicle, * $\mathrm{P}<0.05$ vs. LPS alone.

Fig. 4. Effects of BER on LPS-induced MMPs expression and secretion by macrophages. RAW264.7 cells were pretreated with various concentrations of BER for $1 \mathrm{~h}$ and then stimulated with LPS $(0.1 \mu \mathrm{g} / \mathrm{ml})$ for 6 $\mathrm{h}$ or $12 \mathrm{~h}$. The expression (6 h) and secretion (12 h) of MMP-2 and MMP-9 were determined by RT-PCR (A and C) and ELISA (B and D). Data were obtained from 3 independent experiments: \# $\mathrm{P}<0.05$ vs. Vehicle, ${ }^{*} \mathrm{P}<0.05$ vs. LPS alone.

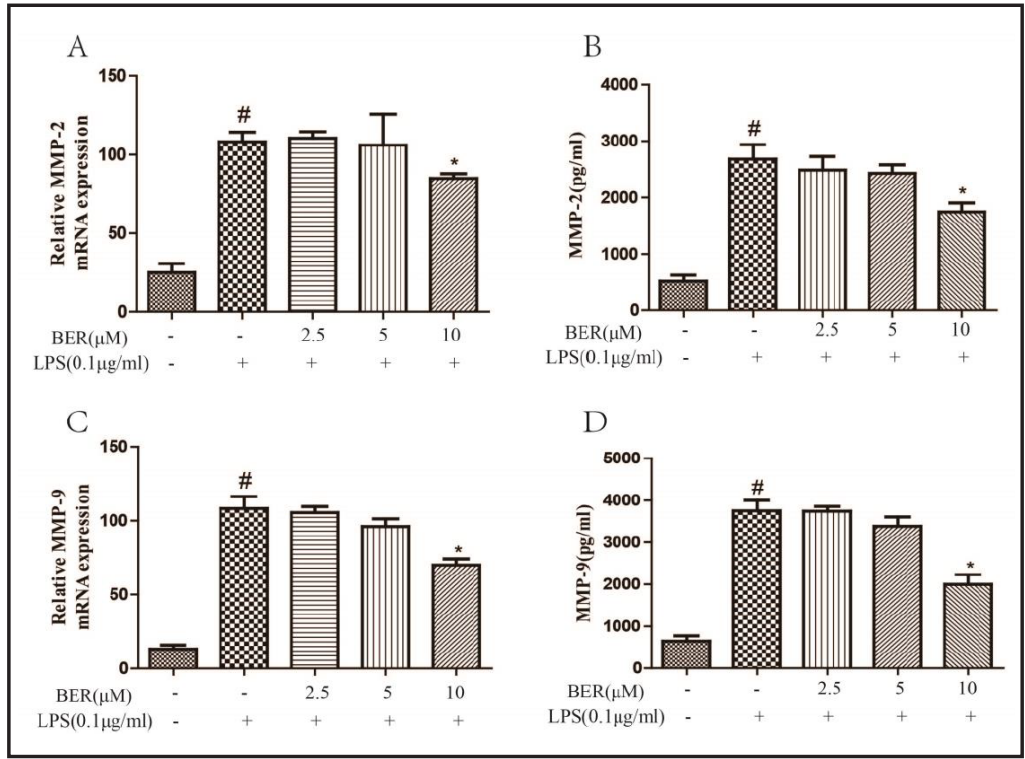

Effects of BER on LPS-induced MMPs expression and secretion by macrophages

During inflammatory response, MMPs produced by macrophages also play important roles and contribute to infiltration of leukocytes into tissues[7, 8, 21]. Therefore, we investigated the effects of BER on LPS-induced MMP-2 and MMP-9 expression, as well as secretion by macrophages. The results (Fig. 4) indicate that BER slightly suppresses mRNA transcription and protein secretion of MMP-2 and MMP-9 by macrophages in concentration of $10 \mu \mathrm{M}$.

\section{Effects of BER on neutrophil activation}

During inflammatory response, neutrophils form another important cell type. After determining the inhibitory effects of BER on the activation of and cytokine secretion by 
Fig. 5. Effects of BER on the activation of neutrophils. Isolated neutrophils were pretreated with various concentrations of BER for 1 $\mathrm{h}$ and then stimulated with fMLP (10M) for 2 h. The levels of CD11b (A) and CD62L (B) on neutrophils were determined by flow cytometry.

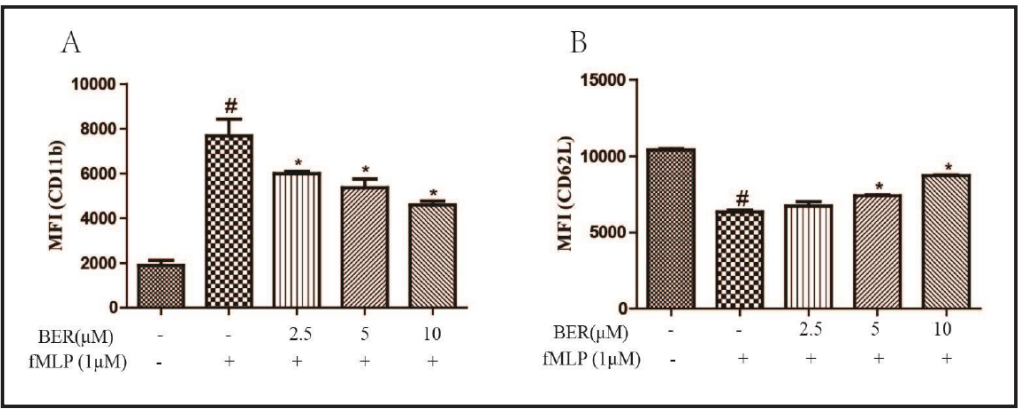

Data were obtained from three independent experiments: \# $\mathrm{P}<0.05$ vs. Vehicle, ${ }^{*} \mathrm{P}<0.05$ vs. fMLP alone.

Fig. 6. Effects of BER on the activation of neutrophils. Isolated neutrophils were pretreated with various concentrations of BER for $1 \mathrm{~h}$ and then stimulated with fMLP (10M) for $2 \mathrm{~h}$. The superoxide release was determined by WST-1 reduction test. Data were obtained from three independent experiments: \# $\mathrm{P}<0.05$ vs. Vehicle, ${ }^{*} \mathrm{P}<0.05$ vs. fMLP alone.
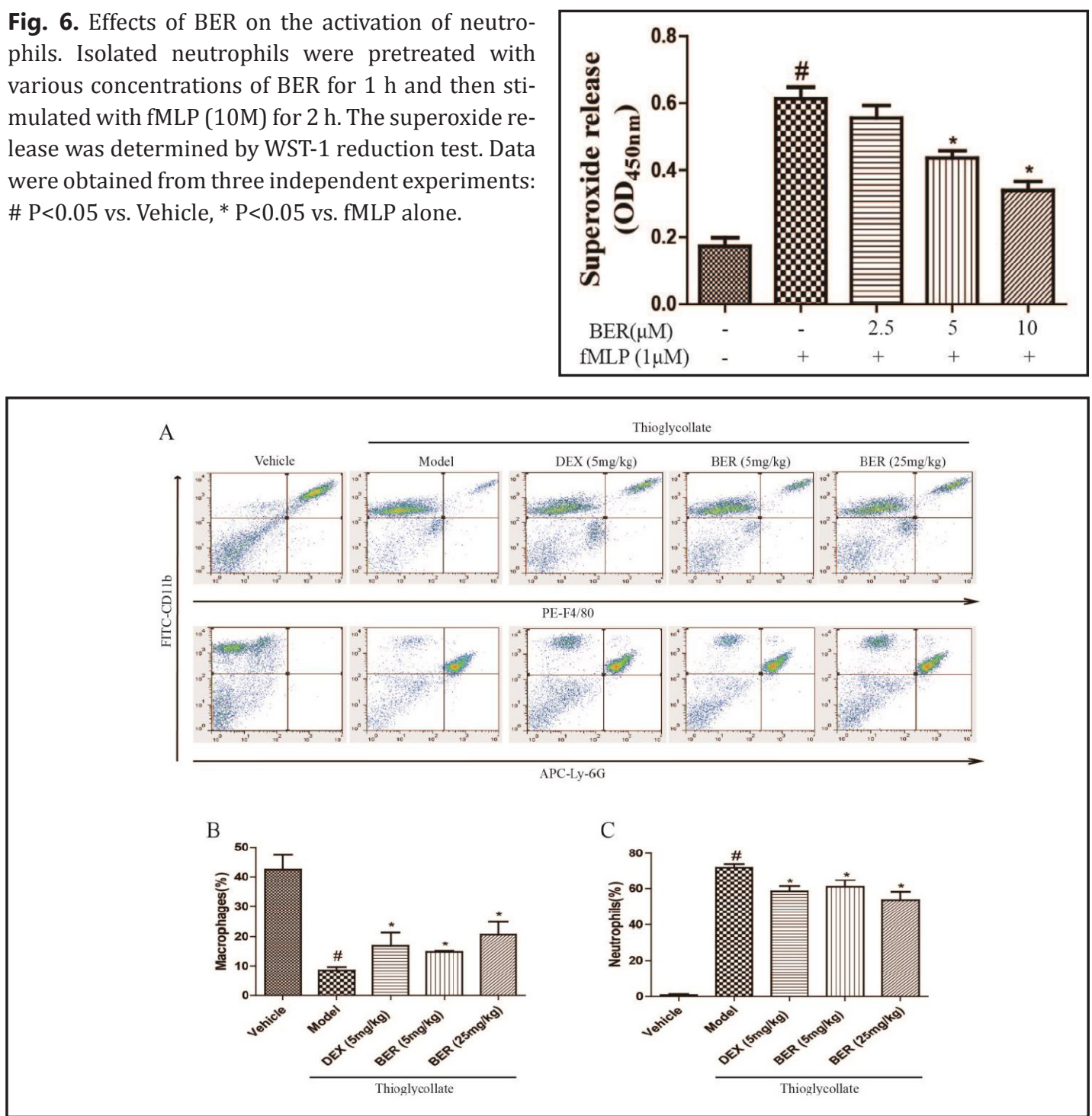

Fig. 7. Inhibitory effects of BER on the activation and infiltration of innate immune cells in peritonitis model. BALB/c mice were orally administered different doses of BER and dexamethasone (DEX) for 1h,then were administered $2 \mathrm{ml}$ of $3 \%$ thioglycollate medium (TM) by intraperitoneal injection. Four hours after administration of TM, subject peritonea were lavaged with $5 \mathrm{ml}$ of PBS and lavage fluids were collected. The percentages of macrophage and neutrophil in lavage fluids were analyzed by flow cytometry (A, B and C). Data were obtained from 3 independent experiments: \# $\mathrm{P}<0.05$ vs. Vehicle, ${ }^{*} \mathrm{P}<0.05$ vs. Model (TM alone). 


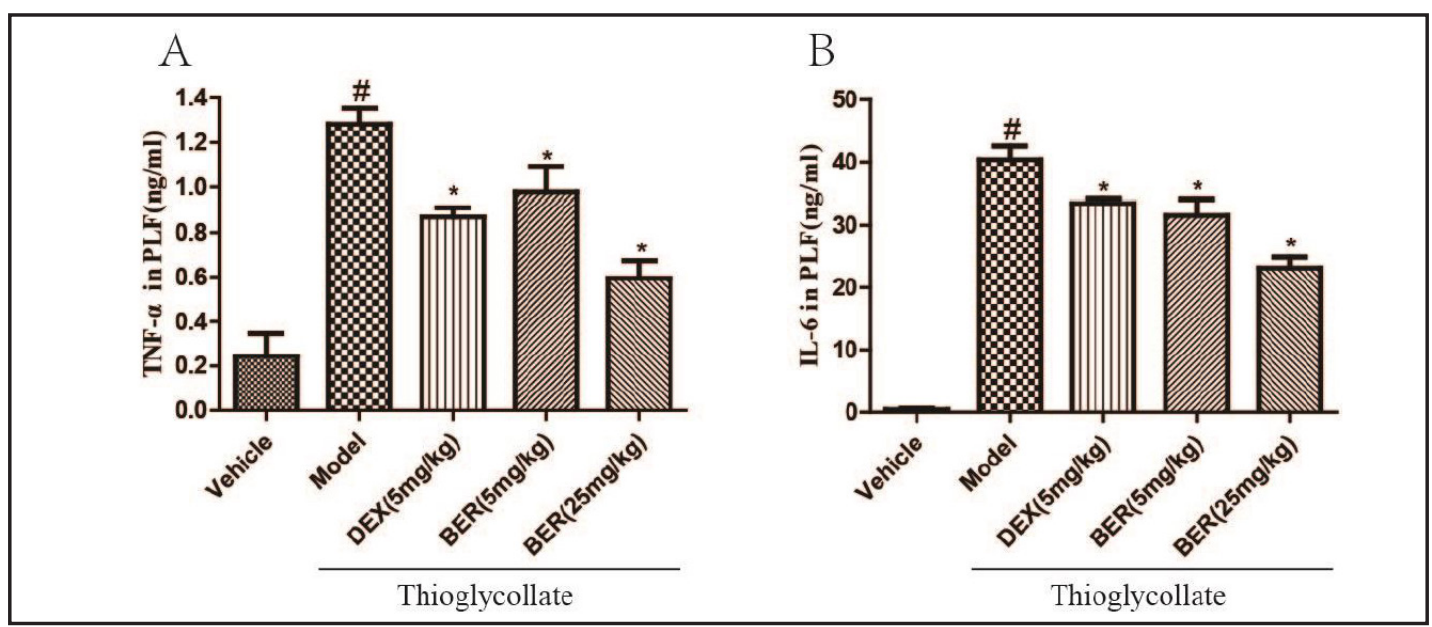

Fig. 8. Inhibitory effects of BER on the production of cytokines in peritonitis model. BALB/c mice were orally administered different doses of BER and dexamethasone (DEX) for $1 \mathrm{~h}$, then were administered $2 \mathrm{ml}$ of $3 \%$ thioglycollate medium (TM) by intraperitoneal injection. After administration of TM for $4 \mathrm{~h}$, subject peritonea were lavaged with $5 \mathrm{ml}$ of PBS and lavage fluids were collected. The concentrations of TNF- $\alpha$ and IL-6 in lavage fluids were determined by ELISA (A and B). Data were obtained from 3 independent experiments: \# $\mathrm{P}<0.05$ vs. Vehicle, ${ }^{*} \mathrm{P}<0.05$ vs. Model (TM alone).

macrophages, we also investigated the effects of BER on the activation of neutrophils. Our results (Fig. 5) show that BER significantly suppresses up-regulation of CD11b and downregulation of neutrophils at $2.5-10 \mu \mathrm{M}$ in a dose-dependent manner.

\section{Effects of BER on the production of superoxide by neutrophils}

Superoxide release by hyper-activated neutrophils is the main cause of tissue damage during inflammatory response. After determining the inhibitory effects of BER on the activation of neutrophils, we further investigated the effects of BER on superoxide release by neutrophils. Here, results (Fig. 6) indicate that BER intensively inhibits superoxide release by neutrophils in a dose-dependent manner at 2.5-10 $\mu \mathrm{M}$.

\section{Effects of BER on peritonitis}

Following determination of the inhibitory effects by BER on the activation of macrophages and neutrophils, anti-inflammatory effects in vivo and therapeutic potential for treatment of inflammatory disease were investigated. In the mouse peritonitis model study, results (Fig. 7) demonstrate that the population of neutrophils in peritoneal cavities of subject mice significantly increased after stimulation by $3 \% \mathrm{TM}$, while the number of macrophage intensively decreased. BER, just like dexamethasone, significantly suppressed the up-regulation of neutrophils and the down-regulation of macrophages at 5 and $25 \mathrm{mg} / \mathrm{kg}$. Furthermore, BER also significantly inhibited the production of TNF- $\alpha$ and IL- 6 in peritoneal cavity at the same concentration (Fig. 8).

\section{Effects of BER on the activation of NF- $\kappa B$ and MAPK signaling pathways}

Previous research establishes that NF- $\kappa B$ and MAPK signaling pathways play critical roles during inflammatory response regulation. In order to investigate the underlying mechanism of BER inflammatory response inhibition, the effects of BER on the activation of

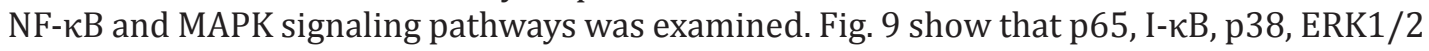
and JNK were highly phosphorylated in LPS-treated RAW264.7 cells and the phosphorylation levels of p65, I- $\mathrm{BB}$ and JNK were significant inhibited by BER, in a dose-dependent manner at 2.5-10 $\mu \mathrm{M}$. Furthermore, BER could significantly inhibit the phosphorylation of ERK1/2 at $10 \mu \mathrm{M}$.

\section{KARGER}


Fig. 9. Effects of BER on the activation of NF- $\mathrm{KB}$ and MAPK signaling pathways. RAW264.7 cells were pretreated with various concentrations of BER for $1 \mathrm{~h}$, and then stimulated with LPS $(0.1 \mu \mathrm{g} / \mathrm{ml})$ for 30 min. The expression of $\mathrm{p} 65$, I-кB, p38, ERK1/2, JNK and their phosphorylated forms was determined by Western blot and band density was analyzed using Quantity One. A typical result from 3 independent experiments is shown: \# $\mathrm{P}<0.05$ vs. Vehicle, ${ }^{*} \mathrm{P}<0.05$ vs. LPS alone.

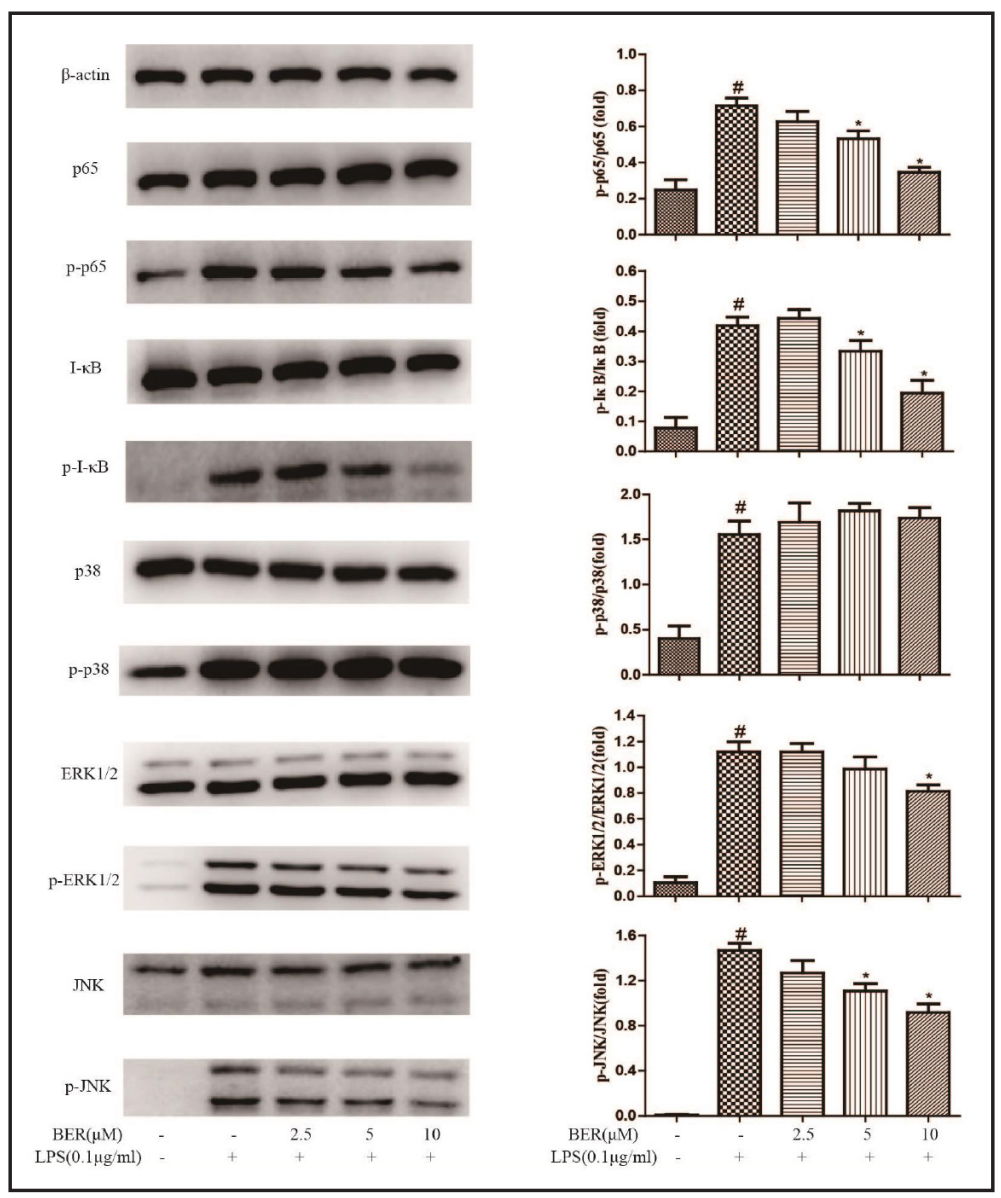

\section{Discussion}

Studies confirm that over-activation of innate immune cells plays a critical role in the pathogenesis of local and systemic inflammatory disorders. As well, results here suggest that controlling activation of macrophages and neutrophils can attenuate inflammatory disorders [1-6]. Previous studies have shown that BER and its derivatives can inhibit tumor growth by modulating NF- $\mathrm{BB}$ signaling pathway and apoptosis[14, 21-24]. In this study, we first determined cytotoxicity of BER on macrophages and neutrophils by cell viability and apoptosis assays, which results indicate that BER is not cytotoxic on macrophages and neutrophils at concentrations up to $50 \mu \mathrm{M}$. Next, we investigated anti-inflammatory effects of BER in vitro under the previous dosages without cytotoxic result.

Macrophages play very important roles during inflammatory response by secreting pro-inflammatory factors, such as TNF- $\alpha$, IL-6 and IL-1 $\beta$ [25-27]. By use of LPS-induced macrophages, we determined the effects of BER on the expression and secretion of the proinflammatory factors, TNF- $\alpha$, IL- 6 and IL- $1 \beta$. Here, results indicate that BER intensively inhibits the expression and secretion of TNF- $\alpha$, IL- 6 and IL- $1 \beta$, thus showing potential anti-inflammatory activity. PGE2 is another key mediator of inflammatory secretion by macrophages and contributes to pain hypersensitivity by promoting sensory neuron hyperexcitation. Inhibition of COX2 expression, which is the key synthase of PGE2, as well as synthesis of PGE2 during inflammation, can significantly attenuate inflammatory pain [28, 29]. In order to comprehensively clarify the anti-inflammatory activity of BER, we determined the effects of BER on the expression of COX2 and PGE2 production, which results show that BER also intensively inhibits the expression of COX2 and PGE2 production by macrophages. In addition, macrophages can release MMPs to facilitate infiltration of immune cells during inflammatory response[7, 8]. So we also evaluated the effects of BER on the expression and 
secretion of MMP2 and MMP-9. The results show that BER slightly suppresses the expression and secretion of MMP-2 and MMP-9 which is consistent with previous report in human breast cancer [21].

Another important innate immune cell type is the neutrophil, which plays key roles during inflammatory response. At sites of inflammation, pro-inflammatory factors induce the transition of circulating neutrophils from a quiescent, poorly-adhesive state to a primed, strongly-adhesive phenotype $[30,31]$. Through the release of reactive oxygen radicals, digestive enzymes and antimicrobial peptides, neutrophils then eliminate the invading microorganisms, coincidentally damaging normal tissues in cases inflammatory disease [3234]. In this study, the effects of BER on the expression of adhesive molecules are defined, which results show that BER significantly inhibits down-regulation of CD11b and upregulation of CD62L on the surface of neutrophils. Furthermore, we found that BER also inhibits superoxide release by fMLP-stimulated neutrophils.

Once the inhibitory effects of BER on the activation of macrophages and neutrophils were determined in vitro, the anti-inflammatory effects of BER were elucidated through a mouse peritonitis model. In this case, results show that macrophages significantly decrease, neutrophils intensively increase and exhibit strong inflammatory response in the peritoneal cavity of test subjects after thioglycollate medium injection. The administration of BER remarkably inhibited consumption by macrophages and exudation of neutrophils. In addition, BER also suppressed the production of the pro-inflammatory factors, TNF- $\alpha$ and IL-6.

NF- $\kappa \mathrm{B}$ and MAPK signaling pathways play key roles in signal transduction during inflammatory response [35-38]. After determining the anti-inflammatory effects of BER, experiments in vitro and in vivo clarified the underlying mechanism by monitoring the activation of NF- $\kappa B$ and MAPK signaling pathways as induced by LPS. Again, results show that BER significantly suppresses phosphorylation of p65, IкB, JNK and ERK1/2.

In summary, a series of mutually-qualifying tests demonstrate that BER exerts antiinflammatory effects by inhibiting the activation of macrophages and neutrophils through the blocking NF- $\kappa$ B, ERK1/2 and JNK signaling pathways. Thus, BER shows great potential for development drug therapy against inflammatory disorders.

\section{Acknowledgements}

This work was supported by Guangdong Natural Science Foundation (2015A030313889, 2014A030313709, and 2014A030313710), Shenzhen Science and Technology Planning Project (ZDSYS201504301045406, JCYJ20150403110829621, GCZX2015060211261472), and Shenzhen Health and Family Planning Commission Project (201401026).

\section{Disclosure Statement}

The authors have no conflict of interest to report in relation to this manuscript.

\section{References}

1 Fujiwara N, Kobayashi K: Macrophages in inflammation. Curr Drug Targets Inflamm Allergy 2005;4:281286.

2 Wynn TA, Barron L: Macrophages: master regulators of inflammation and fibrosis. Semin Liver Dis 2010;30:245-257.

3 Kinne RW, Brauer R, Stuhlmuller B, Palombo-Kinne E, Burmester GR: Macrophages in rheumatoid arthritis. Arthritis Res 2000;2:189-202. 


\section{Cellular Physiology Cell Physiol Biochem 2017;41:2307-2318 \begin{tabular}{l|l} 
and Biochemistry & DOI: 10.1159/000475650 \\
(c) 2017 The Author(s). Published by S. Karger AG, Basel \\
www.karger.com/cpb
\end{tabular}

4 Mocsai A: Diverse novel functions of neutrophils in immunity, inflammation, and beyond. J Exp Med 2013;210:1283-1299.

5 Fournier BM, Parkos CA: The role of neutrophils during intestinal inflammation. Mucosal Immunol 2012;5:354-366.

6 Kolaczkowska E, Kubes P: Neutrophil recruitment and function in health and inflammation. Nat Rev Immunol 2013;13:159-175.

7 Gong Y, Hart E, Shchurin A, Hoover-Plow J: Inflammatory macrophage migration requires MMP-9 activation by plasminogen in mice. J Clin Invest 2008;118:3012-3024.

8 Yiqin Y, Meilin X, Jie X, Keping Z: Aspirin inhibits MMP-2 and MMP-9 expression and activity through PPARalpha/gamma and TIMP-1-mediated mechanisms in cultured mouse celiac macrophages. Inflammation 2009;32:233-241.

-9 Wei X, Zhang B, Zhang Y, Li H, Cheng L, Zhao X, Yin J, Wang G: Hydrogen Sulfide Inhalation Improves Neurological Outcome via NF-kappaB-Mediated Inflammatory Pathway in a Rat Model of Cardiac Arrest and Resuscitation. Cell Physiol Biochem 2015;36:1527-1538.

10 Wong CW, Seow WK, O'Callaghan JW, Thong YH: Comparative effects of tetrandrine and berbamine on subcutaneous air pouch inflammation induced by interleukin-1, tumour necrosis factor and plateletactivating factor. Agents Actions 1992;36:112-118.

11 Wong CW, Thong YH, Seow WK: Comparative effects of tetrandrine and berbamine on guineapig airway microvascular leakage induced by platelet-activating factor and other allergic mediators. Int J Immunopharmacol 1993;15:185-193.

12 Seow WK, Ferrante A, Summors A, Thong YH: Comparative effects of tetrandrine and berbamine on production of the inflammatory cytokines interleukin-1 and tumor necrosis factor. Life Sci 1992;50:PL5358.

13 Hou ZB, Lu KJ, Wu XL, Chen C, Huang XE, Yin HT: In vitro and in vivo antitumor evaluation of berbamine for lung cancer treatment. Asian Pac J Cancer Prev 2014;15:1767-1769.

14 Liang Y, Xu RZ, Zhang L, Zhao XY: Berbamine, a novel nuclear factor kappaB inhibitor, inhibits growth and induces apoptosis in human myeloma cells. Acta Pharmacol Sin 2009;30:1659-1665.

15 Wei YL, Liang Y, Xu L, Zhao XY: The antiproliferation effect of berbamine on k562 resistant cells by inhibiting NF-kappaB pathway. Anat Rec (Hoboken) 2009;292:945-950.

-16 Chen J, Chen Y, Chen Y, Yang Z, You B, Ruan YC, Peng Y: Epidermal CFTR Suppresses MAPK/NF-kappaB to Promote Cutaneous Wound Healing. Cell Physiol Biochem 2016;39:2262-2274.

17 Song L, Kang C, Sun Y, Huang W, Liu W, Qian Z: Crocetin Inhibits Lipopolysaccharide-Induced Inflammatory Response in Human Umbilical Vein Endothelial Cells. Cell Physiol Biochem 2016;40:443-452.

- 18 Chen Z, Chen Y, Pan L, Li H, Tu J, Liu C, Dai X, Zhang X, Sun G, Feng D: Dachengqi Decoction Attenuates Inflammatory Response via Inhibiting HMGB1 Mediated NF-kappaB and P38 MAPK Signaling Pathways in Severe Acute Pancreatitis. Cell Physiol Biochem 2015;37:1379-1389.

-19 Jia X, Wang F, Han Y, Geng X, Li M, Shi Y, Lu L, Chen Y: miR-137 and miR-491 Negatively Regulate Dopamine Transporter Expression and Function in Neural Cells. Neurosci Bull 2016;32:512-522.

20 Xiong H, Xu Y, Tan G, Han Y, Tang Z, Xu W, Zeng F, Guo Q: Glycyrrhizin ameliorates imiquimod-induced psoriasis-like skin lesions in BALB/c mice and inhibits TNF-alpha-induced ICAM-1 expression via NFkappaB/MAPK in HaCaT cells. Cell Physiol Biochem 2015;35:1335-1346.

21 Wang S, Liu Q, Zhang Y, Liu K, Yu P, Liu K, Luan J, Duan H, Lu Z, Wang F, Wu E, Yagasaki K, Zhang G: Suppression of growth, migration and invasion of highly-metastatic human breast cancer cells by berbamine and its molecular mechanisms of action. Mol Cancer 2009;8:81.

22 Zhao Y, Lv JJ, Chen J, Jin XB, Wang MW, Su ZH, Wang LY, Zhang HY: Berbamine inhibited the growth of prostate cancer cells in vivo and in vitro via triggering intrinsic pathway of apoptosis. Prostate Cancer Prostatic Dis 2016;19:358-366.

23 Liang Y, He X, Li X, Zhang X, Zhang X, Zhang L, Qiu X, Zhao X, Xu R: 4-Chlorbenzoyl Berbamine, a Novel Derivative of the Natural Product Berbamine, Potently Inhibits the Growth of Human Myeloma Cells by Modulating the NF-kappaB and JNK Signalling Pathways. Cancer Invest 2016;34:496-505.

24 Du HP, Shen JK, Yang M, Wang YQ, Yuan XQ Ma QL, Jin J: 4-Chlorobenzoyl berbamine induces apoptosis and G2/M cell cycle arrest through the PI3K/Akt and NF-kappaB signal pathway in lymphoma cells. Oncol Rep 2010;23:709-716. 


\section{Cellular Physiology Cell Physiol Biochem 2017;41:2307-2318 \begin{tabular}{l|l} 
and Biochemistry 10.1159/000475650 & $\begin{array}{l}\text { O 2017 The Author(s). Published by S. Karger AG, Basel } \\
\text { www.karger.com/cpb }\end{array}$
\end{tabular}

25 Smolen JS, Steiner G: Therapeutic strategies for rheumatoid arthritis. Nat Rev Drug Discov 2003;2:473488.

26 Wilms H, Sievers J, Rickert U, Rostami-Yazdi M, Mrowietz U, Lucius R: Dimethylfumarate inhibits microglial and astrocytic inflammation by suppressing the synthesis of nitric oxide, IL-1beta, TNF-alpha and IL-6 in an in-vitro model of brain inflammation. J Neuroinflammation 2010;7:30.

27 Dinarello CA, Simon A, van der Meer JW: Treating inflammation by blocking interleukin-1 in a broad spectrum of diseases. Nat Rev Drug Discov 2012;11:633-652.

-28 Zhang Y, Shaffer A, Portanova J, Seibert K, Isakson PC: Inhibition of cyclooxygenase-2 rapidly reverses inflammatory hyperalgesia and prostaglandin E2 production. J Pharmacol Exp Ther 1997;283:1069-1075.

-29 Ulmann L, Hirbec H, Rassendren F: P2X4 receptors mediate PGE2 release by tissue-resident macrophages and initiate inflammatory pain. EMBO J 2010;29:2290-2300.

30 Mocsai A, Zhou M, Meng F, Tybulewicz VL, Lowell CA: Syk is required for integrin signaling in neutrophils. Immunity 2002;16:547-558.

31 Mocsai A, Abram CL, Jakus Z, Hu Y, Lanier LL, Lowell CA: Integrin signaling in neutrophils and macrophages uses adaptors containing immunoreceptor tyrosine-based activation motifs. Nat Immunol 2006; 7:1326-1333.

32 Guzik TJ, Korbut R, Adamek-Guzik T: Nitric oxide and superoxide in inflammation and immune regulation. J Physiol Pharmacol 2003;54:469-487.

-33 Yang SC, Chung PJ, Ho CM, Kuo CY, Hung MF, Huang YT, Chang WY, Chang YW, Chan KH, Hwang TL: Propofol inhibits superoxide production, elastase release, and chemotaxis in formyl peptide-activated human neutrophils by blocking formyl peptide receptor 1. J Immunol 2013;190:6511-6519.

-34 Hwang TL, Shen HI, Liu FC, Tsai HI, Wu YC, Chang FR, Yu HP: Ursolic acid inhibits superoxide production in activated neutrophils and attenuates trauma-hemorrhage shock-induced organ injury in rats. PLoS One 2014;9:e111365.

35 McCulloch CA, Downey GP, El-Gabalawy H: Signalling platforms that modulate the inflammatory response: new targets for drug development. Nat Rev Drug Discov 2006;5:864-876.

36 O'Neill LA: Targeting signal transduction as a strategy to treat inflammatory diseases. Nat Rev Drug Discov 2006;5:549-563.

37 Tak PP, Firestein GS: NF-kappaB: a key role in inflammatory diseases. J Clin Invest 2001;107:7-11.

-38 Thalhamer T, McGrath MA, Harnett MM: MAPKs and their relevance to arthritis and inflammation. Rheumatology (Oxford) 2008;47:409-414. 